\title{
Inner Speech Modification and Young Offender Re-offence: Literature Review and Implications
}

\author{
Jessica Elsom \\ Department of Psychology*, Mount Royal University \\ 4825 Mount Royal Gate, Calgary, AB, T3E 6K6 \\ Jdelsom@shaw.ca
}

*Originally written for a directed reading course for the psychology program at Mount Royal University. Thank you to Dr. Alain Morin for your outstanding support, patience, and guidance.

Review Editors

David Aveline ${ }^{1}$, Alain Morin², Derek Phung ${ }^{3}$

Editors

Brooke Ruskin ${ }^{4}$, Famira Racy 5

\begin{abstract}
Inner speech is the voice in our heads that serves a variety of functions, and impacts individuals' thoughts and behaviours. It is thought that young offenders have misguiding inner voices, and there is hope that professionals can change this through inner speech modification. During treatment, practitioners attempt to teach young offenders to use skills and tools. Ideally, this will reduce recidivism rates and allow these youth to become contributing members of society. In this literature review, the relationship between inner speech and young offender reoffence is examined. The purpose of this research is to bridge literature on inner speech, cognitive behavioural therapy, and young offender research to provide a source of suggestions for reducing delinquent behaviours. I advocate for inner speech modification programs in young offender rehabilitation because the research presented in this review supports the use of inner speech in behaviour modification. I argue that the programs designed for young offenders need continued flexibility, and that there needs to be an increase in availability of programs for young offenders, especially ones involving inner speech modification. I also suggest that researchers should examine more preventative, earlier intervention programs, and investigate the relationships between inner speech and language deficiencies in young offenders.
\end{abstract}

Keywords: self-talk $\cdot$ inner speech $\cdot$ inner speaking $\cdot$ inner voice $\cdot$ verbal mediation $\cdot$ young offenders $\cdot$ juvenile delinquents $\cdot$ recidivism $\cdot$ re-offence $\cdot$ punishment $\cdot$ rehabilitation $\cdot$ inner speech modification $\cdot$ behaviour modification $\cdot$ cognitive behavioural therapy

1 Ph.D. · Department of Sociology \& Anthropology $\cdot$ Mount Royal University

2 Ph.D. · Department of Psychology $\cdot$ Mount Royal University

${ }^{3}$ B.A. $\cdot$ Psychology Student $\cdot$ Mount Royal University

${ }^{4}$ B.Ed.; B.A. · Psychology Student · Mount Royal University

5 M.A. Psychology $\cdot$ Adler University 
Inner speech is the inner conversation or dialogue humans commonly experience (also see inner speaking'; Hurlburt, Heavy, \& Kelsie 2013), where speech specifically about the self is called self-talk by some researchers (Alderson-Day \& Fernyhough 2015; Fernyhough 2016). Researchers are just beginning to identify the neuroanatomy and functions involved with inner speech (e.g., Morin 2015, 2018). Inner speech can aid or handicap individuals depending on the content and frequency. For example, negative inner speech (e.g., rumination or frequent self-criticism) is potentially more debilitating than positive (e.g., self-motivational) inner speech is supportive (Morin 2012). Under the current Youth Criminal Justice Act (YCJA) by the Government of Canada (2015), young offenders are 7 to 17 years old. In general, seminal researchers have found that the offending population has a lower IQ than the non-offending population, come from lower income and larger families, and that their parents are commonly considered inadequate while typically having criminal records themselves (West 1982). Notably this research is dated and these claims are disputed due to implications and third factors. More recently, researchers have found that young offenders report higher drug and alcohol use, have delinquent friends, have little parental supervision, and their values are rooted in obtaining money and materialism both quickly and easily (Savoie 2006; Inderbitzin 2007). Within juvenile detention centres, youth are likely to have two or more disorders occurring at the same time, and they typically score below average on language and social skills tests (Teplin, Abram, McClelland, \& Dulcan 2003). Since it is thought that young offenders have misguided inner voices, practitioners often attempt to modify the youths' inner voice and give them skills and tools for when they return to their daily lives (e.g., Miller 1988, 2011). In this paper, inner speech and young offenders are explored individually, then specific modifications in these contexts are examined, and finally I make suggestions for practical applications and future research.

\section{Methodology}

For this literature review, the writer compiled primary and secondary research through available journals by searching the terms: self-talk, inner speech, young offenders, juvenile delinquents, behaviour modification, and cognitive behavioural therapy in the Mount Royal University and Google Scholar databases. This topic was chosen as the literature is lacking overview of research, including key techniques, best practices, and arguments for practical applications for those specifically interested in using inner speech modification in young offender rehabilitation. It would be difficult to study these applications and practices through a novel experiment in this case, due to time, ethical restraints, and challenges of gaining a large sample. Yet, the benefits of inner speech modification are evident across various contexts. Therefore, I argue that with the extensive research available across disciplines, a literature review is most appropriate for the purposes of overviewing some key directions available for practical applications and best practices.

\section{Inner Speech}

DEFINING. People typically have an unconscious and conscious (Morin 2012). Consciousness serves multiple functions in humans, including the ability to focus on and process information transmitted from the environment; consciousness is a conceptual foundation for self-awareness and meta-self-awareness. As Morin (2011) states, self-awareness is the ability to focus on the self and process information about the self (e.g., 'I am'), and meta-self-awareness is being aware that one is self-aware (e.g., 'I know that I am'). Humans typically possess these forms of awareness, and inner speech contributes to each of these states. Inner speech is an individual's mechanism of speaking to oneself silently (Morin 2018). Although some researchers use the term 'self-talk' to designate this concept (e.g., Hardy 2006, 2009), selftalk is elsewhere defined as including both self-directed inner (internal) and private (external) speech about the self (Alderson-Day \& Fernyhough 2015). Private speech is when an individual speaks to oneself aloud, and is thought to develop in childhood as a function of social speech, preceding the internalization of private speech as inner speech (Vygotsky 1943/1962). Private speech, inner speech, and selftalk are argued to be predicative or elliptical, meaning that the speech is often condensed and cryptic in nature compared to social speech (e.g., McCarthy \& Fernyhough 2011; Morin 2012; Alderson-Day \& Fernyhough 2015).

FUNCTIONS OF INNER SPEECH. Inner speech has been shown to serve many functions from operating a part of everyday working memory, to playing complex roles for language (Alderson-Day \& Fernyhough 2015). In working memory, inner speech appears to play a key role in the rehearsal stage of memory formation (e.g., Williams, Happe \& Jarrold 2008; Morin 
2012). The rehearsal stage allows repetition of information that is wished to be remembered, such as a phone number, until it is no longer relevant. Inner speech is also used in autobiographical memory as people recall the past partially in a narrative form. In typical silent reading tasks, inner speech appears to be a central tool for pronunciation of words and grammar; therefore, inner speech arguably plays a key role in language (Morin 2012). This claim is further supported by studies of patients with deficits in inner speech, who simultaneously have language disorders such as aphasia (Morin 2009, 2012).

Morin $(2005,2018)$ discusses the potential links between inner speech and self-awareness. These theories include the idea that inner speech and self-awareness have a bi-directional relationship, interacting and serving each other while also serving other executive functions. For example, inner speech and self-awareness interact to facilitate healthy processes such as self-reflection and mindfulness, or unhealthy processes such as self-rumination and self-absorption (Morin 2015). Self-rumination is an unhealthy function where one's inner speech is overly-focused on negative aspects of the self, relating moderately strongly to increased anxiety, lack of self concept clarity and lack of self-control (e.g., Racy, Duhnych, Morin \& Patton 2017). Conversely, self-reflection is to curiously think about oneself in a healthy manner, relating to increased self-concept clarity and self-control (Racy, Duhnych, Morin \& Patton 2017), as well as self-improvement and self-regulation (Trapnell \& Campbell 1999; Morin 2018).

Some links between self-regulation and inner speech have been examined. Individuals appear to self-regulate using inner speech to assist other functions such as switching between multiple tasks (Emerson \& Miyake 2001). Self-regulation through inner speech has been shown to be key for individual selfcontrol, thus contributing to success in goals like budgeting money and higher SAT scores (Baumeister, Schmeichel \& Vohs 2007). Furthermore, inner speech was reported by Morin, Uttl, and Hamper (2011) as associated with other functions such as planning tasks, remembering, and self-motivation. Nevertheless, inner speech is not always positive (Trapnell \& Campbell 1999). For instance, an athlete's performance can worsen with negative selfspeech (e.g., 'I cannot do this, I will fail'); however, athletes have been shown to benefit from positive private talk during practices and positive covert speech during competitions (Hardy 2006). Throughout the literature one can find a vast library of information on the benefits and handicaps of inner speech in sport performance (Hardy 2006).

INDIVIDUAL DIFFERENCES IN INNER SPEECH. Inner speech is personal in nature. In some individuals, it has a cryptic quality and is infrequently smooth and flowing, but with others it has been reported as non-condensed, using full sentences and having a dialogic quality, as if one is having a conversation with oneself (McCarthy-Jones \& Fernyhough 2011). It is believed that this characteristic is a consequence of inner speech deriving from social speech to become condensed and internalized. However, unlike social speech, the acoustic quality of inner speech is rarely reported (Morin 2012). Inner speech content and frequency differs among individuals, and people usually engage in inner speech about themselves (Morin, et al. 2011, 2018). Morin and colleagues (2011) found, in decreasing order, that "... self-evaluation, emotions, physical appearance, relationships, problems, food, behaviour, financial situation, stress, performance, future, education, beliefs, others' opinion of self, hypothetical situations, current self, goals, and desires" were the most frequently reported content of inner speech about oneself in a sample of students (p. 1715).

The same line of research showed that beyond inner speech about oneself, individuals engaged in inner speech about others such as peers, acquaintances, strangers, and intimate partners (Morin, et al. 2011, 2018). Also, while frequency and content of reported inner speech instances differed from person to person, trends showed students reported talking to themselves about current activities (e.g. school, sport, work), the physical environment (usually their most immediate), and temporal events (daily, future and past; Morin et al. 2011). Self-regulation (e.g., planning, problem solving), self-reflection (e.g., emotions, self-motivation, appearance, behavior/performance, autobiography), critical thinking (e.g., evaluating, judging, criticizing), people in general, education, and current events were the most frequently reported inner speech instances in a more current sample of students (Morin et al. 2018). Overall, individual inner speech usually is centered on oneself and what is important to the self (Morin, et al. 2018).

Furthermore, contents of ruminative and reflective inner speech differ (Morin 2015). For example, using the five-factor model of personality, Trapnell 
and Campbell (1999) found strong positive relationships between both neuroticism and rumination, as well as between openness to experience and reflection. The research on individual differences in inner speech is limited, but shows that while the subject of the self may be similar among individuals in their inner speech, every individual probably experiences different qualities, frequencies, and contents of inner speech. In sum, individual differences are expected in a self-related phenomenon but trends suggest that inner speech in general plays important roles in self-reflection, self-regulation, and behaviour.

NEGATIVE INNER SPEECH. As mentioned above, negative inner speech can have a significant impact on an athlete's performance, but negative speech is not solely an experience of athletes (e.g., rumination in typical and atypical samples; Trapnell \& Campbell 1999). In a seminal study, healthy individuals experienced a ratio of 1.7 positive inner speech comments to every negative comment, while a ratio of 1 positive comment to 1 negative comment was found to be dysfunctional to individuals (Schwartz 1986). Further, when individuals were in therapy focused on modifying negative inner speech, a decrease of negative comments was shown to be more effective than an increase of positive comments (Schwartz 1986). Part of this therapy may be handicapped by the rebound effect, where suppression of thoughts actually leads to an amplification of the thought. Therefore, dysfunctional inner speech involved in every day thought is potentially more debilitating than the benefits of positive inner speech in thoughts (Schwartz 1986; Morin 2012). Consequently, the remainder of this paper is focused on how inner speech modification applies to the context of young offender rehabilitation in practice. To understand the importance of individual differences and impacts of negative and positive inner speech in context and in practice, a brief report of history, etiology, and current treatment of young offenders in Canada is presented first.

\section{Young Offenders}

BRIEF History OF LAWS REgaRding YOUNG OFFENDERS. In 1984, the Young Offenders Act (YOA) came into effect in Canada, while the Juvenile Delinquents Act from 1908 was repealed (John Howard Society of Alberta 2007). This act was created to more appropriately address young offenders by holding them responsible and accountable, while taking into consideration their age and mental maturity (Government of Canada 2015). Furthermore, the $Y O A$ represented a view of children as dependents, thus making it society's responsibility to protect them. Moreover, the YOA embodied the view that society has an equal right to protection from a young offender. Lastly, the YOA declared that young offenders have the right to due process to respect the legal rights of the individual (e.g., innocence until proven guilty). On the spectrum of beliefs on how to treat a young offender, arguments tend to rest on either end of a punishment versus rehabilitation spectrum (John Howard Society of Alberta 2007). This means that most critics of the YOA either argue that the punishment is too light on young offenders, or that there is a significant overuse of incarceration. In 2003, Bill C-68, the Youth Criminal Justice Act (YCJA), was introduced to replace the $Y O A$. The YCJA is intended to explicitly outline the principles and objectives of sentencing young offenders. This act further supported accountability and provided proportionate consequences ranging from extrajudicial to formal court proceedings. While the YCJA addresses many issues raised by critics of its predecessors, critiques mirror those of the $Y O A$; either the punishment is too light or too significant (John Howard Society of Alberta 2007). Either way, as it is clear that the punishment model is ineffective at modifying young offender behaviour, and alternatives must be considered.

ETIOLOGY OF DELINQUENT BEHAVIOUR IN YOUNG OFFENDERS. Understanding what factors may lead to offences by Canadian youth has been of great interest. A longitudinal study showed five common characteristics among young offenders (West 1982). As briefly presented in the current introduction, young offenders were likely to score lower on IQ tests, come from large, lower income families with parents deemed inadequate by their social workers, and their parents often had criminal records. However, not all young offenders had these characteristics (West 1982). Young offenders reported higher drug and alcohol use, more delinquent friends, and having less parental supervision than other youth in Canada (Savoie 2006). Inderbitzin (2007) found that young offenders had a strong value system rooted in the materialism and money. However, they lacked the resources and means of obtaining their goals legally. Instead, these youth reported that they were exposed to more illegitimate means of meeting their goals. In one study considering diagnostics and indi- 
vidual differences in etiology, females in juvenile detention centres met the criteria for two or more mental disorders more often than males did (Teplin, Abram, McClelland, \& Dulcan 2003). Nevertheless, both genders were more likely to have two or more disorders than one disorder alone. For example, $56.7 \%$ of females were diagnosed with two or more mental disorders compared to $17.3 \%$ of females with one diagnosis, while $45.9 \%$ of males were diagnosed with two or more mental disorders compared to $20.4 \%$ of males with one diagnosis.

Bryan (2004) argued that young offenders frequently struggle to meet age appropriate expectations for language and speech skills. Similarly, when Snow and Powell (2008) compared young offenders' scores to non-young offenders' scores on language processing and production, social skills, and IQ, they found that young offenders had significantly lower scores on language and social skill measures, and that these deficiencies were independent of IQ. The authors argued that young offenders' social skills and language deficits may be related to one another. However, a significantly positive correlation between these two variables was only found in non-offenders and not in young offenders in this study and no significant correlation between the two variables for offenders. This means more research is needed before making conclusions about the relationship between language and social skills in young offenders.

Research has also shown that young offenders commonly struggle with social competency (Kuperminc, Allen, \& Arthur 1996). Evidence for the importance of language and social communication in inner speech and vice versa (see introduction) supports the current argument for focusing on inner speech in rehabilitation. Arguably, there is a need for research to continue to examine how these factors influence the likelihood of youth offending. With all of this information considered, criminal offences by young people involves a complex interaction of numerous individual factors and external influences (Feinlder \& Byers, 2013), including the potentially critical development and functions of inner speech.

CURRENT TREATMENT OF YOUNG OFFENDERS. Currently, there are two main responses to how young offenders should be treated: punishment and rehabilitation. Punishment comes from the view that sees the youth as a free-willed individual who actively chooses to engage in delinquent behaviour (Feinlder \& Byers 2013), and is aimed at the protec- tion of society. Within a juvenile detention environment operating under this view, there are potential consequences for the youth when they act out, such as a loss of recreation privileges, or positive peer socialization. However, access to these privileges has been shown to improve behaviour, and many argue that young offenders are in dire need of rehabilitation by the point of their first arrest because they have not been 'habilitated' with recreation or positive peer socialization in the first place (Feinlder \& Byers 2013). Arguably then, these consequences may be counterintuitive. Also, discipline as a consequence of offending has resulted in a significant increase in re-offense over a control group (Lipsey 2009). While the author does not suggest that the elimination of punishment is necessary, Lispsey (2009) does argue there needs to be a focus on rewarding positive behaviours and a focus on logical and rational punishment.

Rehabilitation of young offenders is found in many different forms, and each form uses multiple techniques. The common goal is to decrease recidivism among young offenders. According to the literature, Cognitive Behavioural Therapy (CBT) appears to be common, and this usually involves treatment planning, homework for young offenders outside of sessions, cognitive and behavioural interventions, and group therapy (Landenberger \& Lipsey 2005). While not all rehabilitation practices use every one of these tools, each uses a combination to a varying degree. Numerous designs of treatment interventions exist for practitioners to help establish an individual, reliable, and valid treatment process when working with young offenders (Landenberger \& Lipsey 2005), yet the effectiveness of rehabilitation approaches is questionable.

Rehabilitation does not work for every young offender. Some researchers have suggested that the structure of a rehabilitation program has limited potential for effectiveness (Abrams, Kim, \& AndersonNathe 2005). This may occur as rehabilitation is usually set up in a phase process where the youth must accomplish a goal before moving on to the new step and then continuing on until they are seen as 'rehabilitated'. Sometimes within these phases there are certain biases. For instance, there can be an assumption that most of the youth have experienced something traumatic, or their family life must have been horrendous as a child. But not all children who offend have experienced this risk factor. Abrams and colleagues (2005) reported the following scenario in treatment requiring young offenders to examine 
family issues: if a youth said they did not have any family issues, the youth was considered not to be ready for the next step in the process. Therefore, the youth may be required to lie in order to satisfy the program. This rehabilitation flaw could potentially reinforce manipulative and lying behaviour and limit learning of adaptive and vital skills (Abrams et al. 2005). In sum, punishment and rehabilitation interventions may not be effective in their current form, and an approach that considers individual differences linked to rehabilitation and performance, such as inner speech modification, could enhance the effectiveness of interventions.

\section{Inner Speech Modification in Young offender Therapy}

Inner speech, as discussed before, serves many functions for individuals. Ideally, the inner voice helps individuals self-regulate, and this self-regulation, in turn, helps them to become less impulsive (Baumeister, Schmeichel, \& Vohs 2007). Arguably, young offenders may have misguided inner voices pushing them to engage in delinquent behaviours. Some researchers seek to find valid and reliable methods that therapists can use to help young offenders modify, change, and adjust their own inner thoughts (e.g., Landenberger \& Lipsey 2005). Selftalk modification has been used in other therapies from those for athletes with anxiety (Hatzigeorgiadis, Zourbanos, Galanis, \& Theodorakis 2011), to individuals with dysfunctional negative inner speech (Hardy 2009), to impulsive children (Meichenbaum \& Goodman 1971). For example, through inner speech training, impulsive children displayed significant increases in self-control, attention, and IQ (Meichenbaum \& Goodman 1971).

General Cognitive Behavioural Therapy TECHNIQUES WITH INNER SPEECH MODIFICATION. Embedded in most rehabilitation therapies, practitioners may or may not be aware that inner speech modification is a key tool for Cognitive Behavioural Therapy (CBT). Through CBT, young offenders can receive an extensive amount of training on their thinking and decision patterns. These tools allow young offenders to identify and challenge dysfunctional inner speech in thoughts and decision making, and replace it with functional inner speech (Feinlder \& Byers 2013). Further, CBT produces 'cognitive restructuring' through using activities and exercises to identify and modify distortions and errors in the thought patterns of young offenders.
Some CBT training focuses on social interactions such as interpersonal problem-solving and social skills training. Interpersonal problem-solving gives the young offenders an opportunity to gain skills to resolve interpersonal conflict through learning how to compromise and ignore negative peer pressure. Social skills training reinforces positive social behaviours which teaches the youth social cues and challenges them to reflect on the feelings of others (Feinlder \& Byers 2013). Given the involvement of inner speech in self-regulation, problemsolving, interpersonal interactions (Morin, Uttl \& Hamper 2011; Morin, Duhnych, \& Racy 2018), and theory of mind or mentalizing about others' thoughts (Morin, El-Sayeed \& Racy 2015), it makes sense to focus on inner speech modification in cognitive and behavioural restructuring.

Other skills young offenders can learn through CBT are anger control and moral reasoning (Feinlder \& Byers 2013). Anger control gives young offenders techniques to reduce anger arousal by identifying personal triggers and individual cues. Further, young offenders can learn methods to reduce negative stimulation and initiate emotional regulation techniques. Moral reasoning training focuses on improving the young offenders' tools for distinguishing between right and wrong behaviour (Feinlder \& Byers 2013). Moreover, some evidence from the lab supports the involvement of inner speech in emotional regulation and performance or behaviour (e.g., Morin, Duhnych, Racy 2018; Racy et al. 2018).

A majority of these CBT techniques involve adapting and modifying inner speech, usually through a multi-step process, as discussed further below. Theoretically, the skills and thoughts translate into functional cognitive processes that can be used in day to day situations. These may be tools used by young offenders to be more successful in many aspects of life, which may then decrease the chance of re-offence. CBT is generally an extensive and expensive treatment, and a time-consuming process that extends from five to one-hundred and four weeks in length (Landenberger \& Lipsey, 2005). These characteristics of CBT have lead researchers to explore which CBT techniques are most valuable, adding to the current case for focusing on inner speech.

In one meta-analysis, effectiveness of CBT was measured by the recidivism rates for both adult and juvenile offenders, and it was noted that there was no distinction between adults and juveniles in effect 
size (Landenberger \& Lipsey 2005). The authors reported that recidivism encompassed mostly re-arrest, reconviction, incarceration, and other forms of recidivism. The meta-analysis showed that treatment of high risk offenders (compared to no treatment), high quality of treatment implementation, and certain CBT techniques yielded the most effective results. The particular CBT techniques involving inner speech modification that displayed the most significant effects on recidivism were individual counselling, cognitive training, and anger control (Landenberger \& Lipsey 2005). Each of these CBT techniques attempts to modify the behaviour and thoughts of the young offenders and mould their inner voices. Below, each of these CBT techniques is explored in greater detail.

COUNSELLING. Individual attention is most commonly equated to one on one counselling (Lipsey 2009), which allows professionals the opportunity to attempt to mould and influence the juvenile by focusing on feelings, cognition, and behaviours. According to Lipsey (2009), individual counselling has been found to yield the strongest effect on re-offense rates for young offenders over any other form of treatment. Furthermore, researchers suggest that including counselling with other tools may be more promising in reducing recidivism rates than counselling alone (e.g., Evans-Chase \& Zhou 2014).

COGNITIVE TRAINING. Cognitive training has been explored as a reasonable treatment for young offenders as either an extension of counselling, or when individual counselling is unavailable. Cognitive training or cognitive restructuring embraces self-statement modification. This process walks the young offenders through how to challenge negative or handicapping inner speech, exchanging it for positive and supportive inner speech (Bowman \& Auerbach 1982). Cognitive training can work to challenge a wide array of distortions involving self-centeredness, minimizing and mislabeling, assuming the worst, and blaming others (Nas, Brugman \& Koops 2005). To mould these distortions, the treatment process allows youth to talk about the issues while the staff facilitates the process of shaping youths' thoughts and perceptions. In one study of this treatment, young offenders had an additional 30 meetings to focus on anger management, social skills, and social decision making along with cognitive restructuring. Here, the youth decreased in the total number of cognitive distortions, most significantly in distortions involving self-statements: selfcenteredness, minimizing and mislabeling, and blaming others (Nas, Brugman, \& Koops 2005). Furthermore, the youth decreased in covert defiant behaviour such as lying and stealing, but there was no effect on overt behaviour like physical aggression and oppositional defiance. While there is room for investigating the effects of self-statement modification on overt behaviour, overall, the youths' attitudes towards delinquent behaviour was shaped to viewing it more negatively compared to the control group (Nas, Brugman, \& Koops 2005).

Anger Control Techniques. In these techniques, professionals aim to teach young offenders how to use self-regulation in order to control their emotions, like anger, which can help youth to act less impulsively. A variety of programs have been designed around anger regulation, such as Aggression Replacement Training (ART; Glick \& Goldstein 1987). ART is a multimodal program with a variety of psychoeducation tools to help youth recognize their emotions (e.g., emotional reappraisal), proactively respond to triggering situations, and teach them how to regulate in unavoidable circumstances. The program is designed to occur for a minimum of three weeks, featuring three main components: structured learning training, anger control training, and moral education. The structured learning training allows participants to work through 50 skills incorporated into 6 different curriculums including beginning social skills, advanced social skills, skills for dealing with feelings, alternatives to aggression, stress regulation skills, and planning skills. Each curriculum is taught through modelling, role playing, feedback about performance, and then transfer training (i.e. generalizing to everyday).

The second component, based on Feindler, Marriott, and Iwata's Anger Control Training, allows each youth to explore previous anger-causing situations (ACT 1984 as cited in Glick \& Goldstein 1987). Youth are asked to describe the situation and work through identifying their individual triggers and cues of anger. Youth are then asked to explore options of 'reminders' they can tell themselves in these situations (e.g. telling themselves to stay calm) and some 'reducers' they can utilize (e.g. deep breathing). ACT, through the use of reminders, is aimed at modifying and practicing inner speech for use in future situations. The youth are then asked to complete a self-evaluation on their response to the situation and what they could do in the future.

The third component, based on Kohlberg's moral education, is where the youth are exposed to moral dilemmas $(1969,1973$, as cited in Glick \& 
Goldstein 1987). According to Glick and Goldstein (1987), assisting the youth with working through moral dilemmas in this format has contributed to an increase in their moral reasoning. Combining these three components of structured learning, ACT, and moral education, has positively affected incarcerated youth by extending beyond the training environment. There is no consensus about which of these approaches is more effective. For example, Holmqvist, Hill, and Lang's (2009) findings showed no significant difference between results of relation treatment methods (i.e. treatment focusing on relationship between youth and staff) and ACT with a token economy (earning rewards). While Holmqvist and colleagues (2009) provide evidence that other approaches may be just as effective as ACT, this approach is continuously being updated and modified, and is only one of the types of anger control programs available for treatment providers to use.

"THINK IT OVER". One specific therapy for modification of inner speech is the dialogical "Think It Over' technique (Miller 2011). First, youth are encouraged to talk openly and freely and expand on their thoughts. In practice, this method allows staff to teach the youth how to verbalize their experiences and emotions. This teaching is done in a safe space through talking orientations; the program helps instill the belief that people are not to be defined by actions, which allows behaviours to be separated from the individual. Youth can then analyze and restructure erroneous thoughts in a psychological space. This modifies how the youth thinks about not only others and their actions, but also themselves and the crimes they have committed. The youth is also taught to see the narratives through an abused-abuser vantage point, thus extending the process of separating people from their actions in the youth's mind. Although it is not currently possible for researchers to directly access or evaluate thoughts, it is argued that the Think It Over technique facilitates changes of internal thoughts that match the structure of the verbalized thoughts. This means that young offenders may change their inner speech to mirror the techniques they learned in the Think It Over therapy, and reduce the tendency to define individuals by their actions without thinking it through, but rather to consider the thought process involved in actions (Miller 2011).

Goal Modification. Some therapists have attempted to focus on modifying the goals of young offenders. Ideally, through modification of goals, the youth will have attainable and realistic expectations, allowing them to be more successful following their re-emergence to society. In one training school, youth are asked to make short- and long-term goals (Inderbitzin 2007). The staff then attempts to help youth mould their aspirations through (1) modelling conforming behaviours, conversations, programs, workbooks or worksheets, and (2) using empathic but honest and factual statements regarding their goals and about where their choices in life could lead them. Inderbitzin (2007) mentions that the staff encourage the youth to 'aim low' to create realistic visions in the youth's minds for their future goals. Inner speech modification has a potential place in this approach, similar to the other approaches, where verbalizations, personal relevance (goals) and speech related to the self, including interpersonal feedback, facilitate change.

\section{Conclusion: Practical Applications \& Future Research}

While inner speech modification may be a valuable tool for rehabilitation of young offenders, there is a need for consideration of best practices, such as the flexibility of designs and systems to adaptations of individual differences and contexts. Further, young offenders are currently lacking access to necessary treatment, and, in some cases, are being harmed rather than helped (e.g., program structure; Abrams, Kim, \& Anderson-Nathe 2005; punishment versus rehabilitation; John Howard Society of Alberta 2007). Arguably though, inner speech modification may be a leading tool for this population, considering the relationships between inner speech, self-awareness, social cognition, self-regulation and self-control (e.g., Morin 2018). Not only have researchers shown that involvement of inner speech modification can decrease delinquent behaviours within the environment that youth are taught in (e.g., individual counselling, cognitive training, anger control), but these and similar learned skills can be generalized to other environments (e.g., Glick \& Goldstein 1987). Investing into programs involving inner speech modification can provide youth with the skills they need to develop a sense of autonomy in their lives, and to facilitate the ability to make a change if they desire.

Furthermore, I suggest that future researchers should investigate the presence or absence of relations between deficits in both language and social skills in youth who offend. Results could potentially 
inform best practices such as preventive programs for children who are of higher risk or displaying these characteristics (e.g., low verbal mediation of self-regulation and theory of mind). If parents, guardians, teachers, and professionals were given tools to help identify children at risk and engage them in courses or programs to address these risks from an earlier age, there may be a decrease in youth offending. Research should also examine the relationships between inner speech and language deficiency in young offenders. Considering language largely involves inner speech and vice versa (Morin 2012), this investigation could be used to help enhance the youth's language skills and in turn help modify youth's inner speech and vice versa. Similar to the 'Think It Over' program (Miller 2011), researchers and professionals can use this approach to help distinguish and modify divergent inner speech processes of young offenders that contribute to juvenile delinquent behaviours. While direct observation of inner speech and its effects on behaviour is not currently possible, and research extensions along with greater investment in early intervention programs proposed will not prevent all offences by youth, there is evidence to suggest that these considerations may help decrease the rates of youth offence and recidivism. This will save society's resources and more importantly, offer these youth opportunities that may have otherwise been inconceivable.

\section{References}

Abrams, L. S., Kim, K., \& Anderson-Nathe, B. (2005). Paradoxes of treatment in juvenile corrections. Child and Youth Care Forum, 34(1), 7-25. http://doi.org/ 10.1007/s10566-004-0879-3

Alderson-Day, B., \& Fernyhough, C. (2015). Inner speech: Development, cognitive functions, phenomenology, and neurobiology. Psychological Bulletin, 141(5), 931-965. http://doi.org/10.1037/ bul0000021

Baumeister, R., Schmeichel, B. J., \& Vohs, K. D. (2007). Self-regulation and the executive function: The self as controlling agent. In A. W. Kruglanski \& E.T. Higgins (Eds.), Social Psychology (2nd ed., pp. 516-539). New York, NY: Guilford.

Bowman, P. C., \& Auerbach, S. M. (1982). Impulsive youthful offenders: A multimodal cognitive behavioural treatment program. Criminal Justice and Behavior, 9, 432-454.http://doi.org/ 10.1177/0093854882009004003

Bryan, K. (2004). Preliminary study of the prevalence of speech and language difficulties in young offenders. International Journal of Language \& Communication Disorders, 38(3), 391-400. http://doi.org/10.1080/ 13682820410001666376

Emerson, M. J., \& Miyake, A. (2001). The role of inner speech in task switching: A dual-task investigation. Journal of Memory and Language, 48(1), 148168. http://doi.org/10.1016/
S0749-596X(02)00511-9

Evans-Chase, M., \& Zhou, H. (2014). A systematic review of the juvenile justice intervention literature: What it can (and cannot) tell us about what works with delinquent youth. Crime \& Delinquency, 60(3), 451-470. http://doi.org/ 10.1177/0011128712466931

Feinlder, E., \& Byers, A. M. (2013). Chapter 17 cbt with juvenile offenders. In R. C. Tafrate, \& D. Mitchell (Eds.), Forensic CBT: A Handbook for Clinical Practice (pp.377-390). http://doi.org/ 10.1002/9781118589878

Fernyhough, C. (2016). The Voices Within: The History and Science of How We Talk to Ourselves. New York, NY: Basic Books.

Glick, B., \& Goldstein, A. P. (1987). Aggression replacement training. Journal of Counseling \& Development, 65(7), 356362. http://doi.org/10. 1002/j.1556-6676.1987.tb00730x

Government of Canada. (2015). Youth criminal justice act (YCJA). [Canada Justice Laws website]. Retrieved from www.laws-lois.justice.gc.ca

Hardy, J. (2006). Speaking clearly: A critical review of the self-talk literature. Psychology of Sport and Exercise, 7(1), 8197. http://doi.org/10.1016/ j.psychsport.2005.04.002

Hardy, J. (2009). Awareness and motivation to change negative self-talk. The
Sport Psychologist, 23(4), 435-450. Retrieved from http://journals.humankinetics.com

Hatzigeorgiadis, A., Zourbanos, N., Galanis, E., \& Theodorakis, Y. (2011). Self-talk and sports performance: Ameta-analysis. Perspectives on Psychological Science, 6(4), 348-356. http://doi.org/ 10.1177/1745691611413136

Holmqvist, R., Hill, T., \& Lang, A. (2009). Effects of aggression replacement training in young offender institutions. International Journal of Offender Therapy and Comparative Criminology, 53(1). 74-92. http://doi.org/10.1177/ 0306624X07310452

Hurlburt, R. T., Heavey, C. L., \& Kelsey, J. M. (2013). Toward a phenomenology of inner speaking. Consciousness and Cognition, 22(4), 1477-1494

Inderbitzin, M. (2007). Inside a maximum security juvenile training school. Punishment \& Society, 9(3), 235-251. http://doi.org/10.1177/1462474507 077492

John Howard Society of Alberta. (2007). Justice for young offenders. Retrieved from http://johnhoward.ab.ca/ pub/youngoff/youngoff.pdf

Kuperminc, G. P., Allen, J. P., \& Arthur, M. W. (1996). Autonomy, relatedness and male adolescent delinquency: Toward a multidimensional view of social competence.Journal of Adolescent Research, 11(4), 397-420. http://doi.org/ 
$10.1177 / 0743554896114002$

Landenberger, N.A., \& Lipsey, M.W.(2005). The positive effects of cognitive-behavioral programs for offenders: A metaanalysis of factors associated with effective treatment. Journal of Experimental Psychology, 1(4), 451-476. http://doi.org/10.1007/s11292-0053541-7

Lipsey, M. (2009). The primary factors that characterize effective interventions with juvenile offenders: A meta-analytic overview. Victims and Offenders, 4(2), 124-147. http://doi.org/ 10.1080/15564880802612573

McCarthy, S. J., \& Fernyhough, C. (2011). The varieties of inner speech: Links between quality of inner speech and psychopathological variables in a sample of young adults. Consciousness and Cognition, 20(4),1586-1593. http://doi.org/ 10.1016/j.concog.2011.08.005

Meichenbaum, D. H., \& Goodman, J. (1971). Training impulsive children to talk to themselves: A means of developing selfcontrol.Journal of Abnormal Psychology, 77(2),115-126.http://doi.org/ 10.1037/h0030773

Miller, D. L. (2011). Being called to account understanding adolescents' narrative identity construction in institutional contexts. Qualitative Social, 10(3), 311328. http://doi.org/10.1177/ 1473325011409479

Morin, A. (2005). Possible links between self-awareness and inner speech: Theoretical background, underlying mechanisms, and empirical evidence. Journal of Consciousness Studies, 12(4-5), 115-134.

Morin, A. (2009). Self-awareness deficits following loss of inner speech: Dr. Jill Botle Taylor's case study. Consciousness and Cognition, 18(2), 542-529. http://doi.org/10.1016/j.concog.2008.09.008

Morin, A. (2011). Self-awareness part 1: Definition, measures, effects, functions, and antecedents. Social and Personality
Psychology Compass, 5(10), 807-823. http://doi.org/10.1111/j.1751-9004. 2011.00387.x

Morin, A. (2012). Inner speech. In V. S. Ramachandran (Ed.), Encyclopedia of Human Behavior (2 $2^{\text {nd }}$ ed.). Toronto, Canada: Elsevier. http://doi.org/10. 1016/B978-0-12-375000-6.00206-8

Morin, A. (2015). The self-reflective function ofinner speech. [Invited talk]. Presented at the workshop on Inner Speech: Theories and Models. Universidad de Granada. Granada, Spain.

Morin, A. (2018). The self-reflective function of inner speech:Twelve years later. In. P. Langland-Hassan, \& A. Vicente, Eds., Inner Speech Anthology. Oxford: Oxford University Press.

Morin, A., Duhnych, C., Racy, F. (2018). Selfreported inner speech use in university students. Applied Cognitive Psychology, 32(3), 376-382. https://doi.org/ 10.1002/acp.3404

Morin, A., El-Sayed, E., \& Racy, F. (2015). Self-awareness, inner speech, and theory of mind in typical and ASD individuals: A critical review. In E. Sherwood (Ed.), Theory of Mind: Development in Children, Brain Mechanisms and Social Implications, 43-113

Morin, A., \& Uttl, B. (2013). Inner speech: A window into consciousness. Neuropsychotherapist. http://doi.org/10. 12744/tnpt.14.04.2013.01

Morin, A., Uttl, B., \& Hamper, B. (2011). Selfreported frequency, content, and functions of inner speech. Procedia - Social and Behavioral Sciences, 30, 17141718. http://doi.org/10.1016/ j.sbspro.2011.10.331

Nas, C. N., Brugman, D., \& Koops, W. (2005). Effects of EQUIP programme on the moral judgement, cognitive distortions, and social skills of juvenile delinquents. Psychology, Crime \& Law, 11(4), 421434. http://doi.org/10.1080/ 10683160500255703

Racy, F., Duhnych, C., Morin, A., \& Patton, J. (2017). Correlations between several self-related constructs. [poster presentation]. International Conference on Psychology and Behavioural Sciences (ICPBS). Lisbon, Portugal; BASICS, Banff, AB. Retrieved from www2.mtroyal.ab.ca/ amorin/SelfConstructs.pdf

Savoie, J. (2006). Youth self-reported delinquency. Juristat, 27(6). [Statistics Canada - Catalogue no. 85-002-XPE]. Retrieved on September 26, 2015 from http://www.statcan.gc.ca/pub/85002-x/85-002-x2007006-eng.htm

Schwartz, R.M. (1986). The internal dialogue: On the asymmetry between positive and negative coping thoughts. Cognitive Therapy and Research 10, 591-605.

Snow, P. C., \& Powell, M. B. (2008). Oral language competence, social skills and high-risk boys: What are juvenile offenders trying to tell us? Children \& Society, 22(1), 16-28. http:// doi.org/ 10.1111/j.1099-0860.2006.00076.x

Teplin, L. A., Abram, K. M., McClelland, G. M., \& Dulcan, M. K. (2003). Comorbid psychiatric disorders in youth in juvenile detention. Arch Gen Psychiatry, 60(11), 1097-1108. http://doi.org/10.1001/ archpsyc.60.11.1097

Trapnell, P. D., \& Campbell, J. D. (1999). Private self-consciousness and the fivefactor model of personality: Distinguishing rumination from reflection. Journal of Personality and Social Psychology, 76(2), 284-304. http://doi.org /10.1037/0022-3514.76.2.284

Vygotsky, L. S. (1943/1962). Thought and language. Cambridge: MIT Press. West, D. J. (1982). Delinquency, its roots, careers, and prospects. Harvard University Press: Cambridge: Massachusetts.

Williams, D., Happé, F., \& Jarrold, C. (2008). Intact inner speech use in autism spectrum disorder: evidence from a shortterm memory task. Journal of Child Psychology and Psychiatry, 49(1), 51-58. Retrieved from http://core.ac.uk/ download/pdf/10637720.pdf 